\title{
PRINCÍPIOS DA UNIÃO INTERNACIONAL DE TELECOMUNICAÇÕES (UIT) E DO ACORDO SOBRE COMÉRCIO DE SERVIÇOS (GATS) DA OMC
}

\author{
Umberlo Celli Junior**"
}

\begin{abstract}
Resumo:
Esse artigo trata especificamente de dois Tratados Internacionais dos quais o Brasil é signatário, a sabur: o Tratado da I nião Internacional de Telecomunicações (UIT) (1992) e o Acordo Constitutivo da Organização Mundial do Comércio (OMC) (1994). Um dos ancxos do Tratado da UIT é o Regulamento Internacional de Telecomunicações (RIT). que estabelece, em seu Art. 6.1.3., isenção tributária nas remessas ao Exterior entre operadoras de telecomunicações referentes a pagamentos efetuados por contraprestação de serviços de telecomunicações internaciunais. Um dos acordos que fazem parte da OMC é o do GATS, que dispõe sobre a liberalização do comércio de serviços, e que tem no tratamento nacional um de seus princípios fundamentais. O Brasil tem se recusado a reconhecer a plena vigência no país do art. 6.I.3. do RIT. Por outro lado, adotou um modelo de legislação sobre serviços de satélites que fere o principio do tratamento nacional do GATS. Sustenta-se nesse artigo que a natureza vinculativa tanto do art. 6.1.3. do RIT quanto do princípio do tratamento nacional do GATS impõe ao país a obrigação de adotar certas condutas e políticas compativeis com os interesses da comunidade internacional. A relutância em segui-las coloca o Brasil na condição de país que não tem apreço pela segurança jurídica das relações intermacionais nem pela boa-fé no cumprimento das obrigações internacionais.
\end{abstract}

Palavras-chave: Ĺnião Internacional de Telecomunicações. UIT. Organização Mundial do Comércio. OMC. Acordo sobre o Comércio de Serviços. GATS.

\begin{abstract}
:
This article deals specifically with two International Treaties to which Brazil is a party, to wit: the International Telecommunications Union Treaty (ITU) (1992) and the Agreement Establishing the World Trade Organization (WTO) (1994). One of the annexes to the ITU Treaty is the Telecommunications International Regulation (TIR), which Session 6.1.3. sets forth a tax exemption on remittances abroad made by telecommunications operators for payment of international telcommunications services. Among the agreements within the WTO framework is the GATS, which rules are aimed at liberalizing the trade in services based, among other essential principles, on the national treatment principle. Brazilian government has been refusing to accept that Session 6.1.3. of the TIR is in force within the country. Moreover, the Brazilian authorities adopted a satellite service provision regulatory framework which clearly violates the national treatment under GATS. It is submitted in this article that the binding naturc of both Session 6.1.3. of the TIR and the GATS national treatment principle subjects the country to adopting certain policies which
\end{abstract}

O autor dedica esse artigo ao saudoso mestre Professor Guido Fernando Silva Soares.

Professor Doutor de Direito Internacional da Faculdade de Direito da Universidade de São Paulo. 
are compatible with the interests of the international community as a whole. The reluctance to abide to and implement such policies raises the suspicion that the country is neither committed to the relevant legal security in international relations nor to the good faith principle that must govern the intcrnational obligations.

Keywords: International Telccommunication Union (ITU). World Trade Organization (WTO). General Agreement on Trade and Services. GATS.

\section{Introdução}

1.1. Princípios gerais da União Internacional de Telecomunicações ("UIT") e princípios básicos da Organização Mundial do Comércio ("OMC")

$\mathrm{O}$ art. 38 do Estatuto da Corte Internacional de Justiça estipula que, dentre as fontes de Direito Internacional Público, se incluem os princípios gerais de direito reconhecidos pelas nações civilizadas. Sob uma concepção positivista, esses princípios gerais tiveram, durante muito tempo, função meramente auxiliar e integrativa na aplicação do direito. Com o aprofundamento da interdependência econômica dos Estados, no entanto, esse conceito sofreu significativas alterações, a ponto de permitir que muitos doutrinadores atualmente enquadrem os princípios gerais na categoria de norma jurídica vinculante. Essa natureza vinculante dos princípios impõe aos Estados a obrigação de adotar certas condutas e politicas compatíveis com os interesses da comunidade internacional. $\dot{E}$ por isso que muitos desses princípios gerais se encontram consubstanciados em tratados constitutivos de organizações internacionais especializadas da Organização das Nações Unidas, tais como a UIT e a OMC.

Com efeito, alguns princípios gerais de Direito Internacional de Telecomunicações podem ser identificados na UIT, tais como o da utilização para fins pacíficos e de cooperação, da interferência não prejudicial. do interesse público internacional e do serviço satisfatório. 'Para os efeitos deste artigo, interessa conhecer este último, que, na prática, implica não somente a obrigação de se oferecer aos usuários um scrviço de telecomunicações de boa qualidade, como também um serviço de acordo com "parâmetros econômicos adequados" que não impossibilitem seu uso.

Um exemplo de fomento à criação de parâmetros econômicos adequados para a prestação de serviços está contido no art. 6.1.3. do Regulamento Internacional de

\footnotetext{
1 Ver RODRIGUES, José Rubens Andrade Fonseca. Principios Gerais de Direito Inrernacional de Telecomunicação e a I ei n. 9.472/97 da Repriblica Federativa do Brasil ("Lei Geral de Telecomunicações"), 2004. Tese (Doutorado) - Faculdade de Direito da Universidade de São Paulo, São Paulo. p. 67-69.

2 ld., p. 70.
} 
Telecomunicações ("RIT"), que é parte integrante do Tratadu Constitutivo da UIT. Esse artigo do RIT prevê isenção de tributos nas remessas ao exterior entre operadoras de telecomunicações referentes ao pagamento pelo tráfıgo saintı (i.e., pagamentos efetuados por contraprestação de serviços de telecomunicações internacionais). O Brasil, contudo. lastreado nu Parecer da Advocacia Geral da União de No. AGU/SF/01/2000, datado de 28 de setembro de 2000 , e publicado no DOU de $1^{\circ}$ de novembro de 2000 ("Parecer AGU"), tem-sc recusado a reconhecer a vigência dessa isunção tributária. Segundo o Parecer AGL, o RIT não estaria em vigor no país por não ter sido expressamente aprovado pelo Congrusso Nacional nem promulgado por Decreto do presidente da República com subseqüente publicação no DOU.

Já do Acordo de Serviços da OMC ("General Agreement on Trade in Services - GATS") ("GATS") constam os princípios básicos do tratamento nacional e de nação mais favorecida. da transparência e da liberalização progressiva. ${ }^{3}$ Segundo o principio do tratamento nacional, que é o relevante para este trabalho, fornecedores estrangeiros de serviços devem ser tratados como os prestadores e fornecedores nacionais: "cada Membro outorgará aos serviços e prestadores de serviços de qualquer outro Membro, com respeito a todas as medidas que afetem a prestação de serviços, um tratamento não menos favorável do que aquele que dispensa aos seus próprios serviços similares e prestadores de serviços similares" (artigo XVII, 1, do GA TS). Vale observar que um tratamento formalmente idêntico ou formalmente diferente "será considerado menos favorável se modificar as condições de compeitção em favor dos serviços ou prestadores de serviços do Membro em comparação com serviços similares ou prestadores de serviços similares de qualquer outro membro" (artigo XVIl, 3, do GATS).

A Lei n. 9.472, de 16 de julho de 1997, a Lei Geral de Telecomunicações ( "LGT"), estabelece em seu art. 171 que, para a execução de serviço de telecomunicações via satélite, "deverá ser dada preferíncia ao emprego de satélite brasileiro, quando este propiciar condições equivalentes às de terceiros" O emprego de satélite estrangeiro, na forma do parágrafo primeiro deste artigo, "somente será admitido quando sua contratação for feita com empresa constituida segundo as leis brasileiras e com sede e administração no País, na condição de representante legal do operador estrangeiro" Nesse tocante, a Resolução n. 220, de 05 de abril de 2000 ("Resolução n. 220/00"), da Agência Nacional

Trata-se, como lembra Vera Thorstensen, dos mesmos princıpios básicos do GATT: "Para a árca de serviços foi uriado o GATS - Gencral Agrecment on Trade in Services, para ser implementado dentro da nova OMC, baseado nos mesmos principios do GATT" In: OMC: Organizaçào Mundial do l omércio: as regras do Comercio Internacional e a Nova Rodada de Negociaçōes Multilaterais, 2. ed. São Paulo: Aduaneiras, 2001. p. 196. 
de Telecomunicações ("Anatel"), determina que, dentre os requisitos para obtenção de direito de exploração de satélite estrangeiro, deverá a proprietária do segmento espacial ou a pessoa que detém o direito de operá-lo "prover a capacidade do segmento espacial somente através do representantc indicado" Para a Anatel, isso significa que o provimento de capacidade de satélite estrangeiro no Brasil deve ser feito pelo representante legal, por mio de contrato por ele firmado com empresa de telecomunicações no Brasil, e que o correspondente pagamento deve ser efetuado em mocda corrente nacional. ${ }^{4}$

Como será visto mais adiante, esse requisito modilica. na prática, as condições de competição em favor dos serviços ou prestadores de serviços nacionais (i.e., condições menos favoráveis aos operadores de satélites estrangeiros), uma vez que torna inviável, do ponto de vista tributário e financeiro, o provimento de capacidade de satélite estrangeiro no Brasil.

O objetivo deste estudo é. pois. o de demonstrar que: (i) o art. 6.1.3. do RIT está em vigor no Brasil: (ii) ao negar sua vigência, o Brasil está violando o princípio satisfatório da UIT; e (iii) o provimento de capacidade de satélite estrangeiro por meio de representante legal, na forma pretendida pela Anatel, fere não somente o princípio do tratamento nacional do GATS, como também o princípio satisfatório da UIT.

\section{Vigência do Rit e violação do princípio satisfatório}

\subsection{A controvérsia sobre a vigència do RIT}

A vigência no Brasil do RIT, aprovado em 09 de dezembro de 1988, na Conferência Administrativa Mundial Telegráfica da UIT, em Melbourne, Austrália ("Conferência de Melbourne"), tem sido objeto de grande controvérsia. Em vigor internacional desde $1^{\circ}$ de julho de 1990. dispõe tal regulamento sobre as regras e os princípios gerais relacionados à prestação, à operação e à remuneração dos serviços internacionais de telecomunicações. Nos termos do RIT, cada país signatário, dentre os quais o Brasil, obriga-se a tornar disponível o acesso dos demais à sua rede interna de telecomunicações, de forma a permitir a finalização das chamadas internacionais. Assim, uma operadora nacional que tenha dentre suas atividades a prestação de serviço internacional de telecomunicações deverá administrar os envios e os recebimentos de tráfegos internacionais. Quando o tráfego é enviado, ou seja, com a chamada iniciada no

Conforme Oficio Circular Anatel n. 004/PVSSA/PPVSS/2001, de 30 de outubro de 2001 ("Oficio Circular Anatel n. 004/2001"). 
país em que a operadora está localizada com destino ao exterior, tem-sc o "tráfego sainte" ("outbound traffic"); quando o tráfego é recebido, isto é, com a chamada originada no Fxterior e completada no interior daquele país, tem-se o "tráfego entrante" ("inbound traffic").

Para as empresas que prestam serviços de telefonia fixa ("STFC") sob concessão ou autorização da Anatel, notadamente na modalidade Longa Distância Internacional, é imprescindivel a contratação de opcradoras estrangeiras que possam terminar chamadas por elas iniciadas no Brasil. Soh tais contratos, as prestadoras de STFC remuneram as operadoras de telecomunicações situadas no exterior que, por meio de seus circuitos internacionais, finalizam as chamadas originadas no Brasil e destinadas a território estrangeiro. É importante registrar ainda que, quando prestam STFC relativo à terminação de chamadas iniciadas no Exterior e destinadas a um de seus usuários no Brasil, essas empresas também fazem jus a remuneração a ser recebida da operadora de telecomunicações situada no Exterior. É por isso que elas possuem acordos com diversas operadoras estrangeiras com as quais, periodicamente, realizam acerto de contas que ora resultam na remessa de valores ao Exterior, ora no recebimento, dependendo do volume de serviços de telecomunicações tomados ou prestados.

É justamente em relação a essa remessa de valores ao Exterior para remuneração (ou acerto de contas) de operadoras estrangeiras que lhes prestam serviços de terminação de chamadas e de sinal de dados (i.e., contraprestação de serviços de telecomunicações internacionais) que têm surgido algumas dúvidas quanto à incidência do Imposto de Renda na Fonte ("IRRF"). Isso porque, segundo o art. 685, inciso II, "a" do Regulamento do Imposto de Renda instituido pelo Decreto n. 3.000, de 26 de março de 1999, nas rumessas ao Exterior, decorrentes de pagamentos pela prestação de serviços, há retenção do IRRF pela alíquota de $25 \%$. Contudo, nos termos do RIT, os pagamentos efetuados por contraprestação de serviços de telecomunicações internacionais (i.e., pagamento pelo tráfego sainte) não podem ser objeto de incidência de nenhum tributo. É o que prescreve o art. 6.1.3. verbis:

6.1.3. Nu caso de a legislação nacional de um país prever a aplicação de uma taxa fiscal sobre a taxa de percepção para os serviços internacionais de telecomunicações, essa taxa fiscal só surá normalmente cobrada pclos serviços internacionais faturados aos clientes deste pais, a menos que outros acordos tenham sido celebrados para endereçar circunstâncias especiais. 
Ou seja, de acordo com o art. 6.1.3. do RIT transcritu acima, há isenção de tributos nas remessas ao exterior entre operadoras de telecomunicações referentes ao pagamento pelo tráfego sainte ("outbound traffic").

$\mathrm{Na}$ jurisprudência das Delegacias de Julgamento da Receita Federal da $7^{\mathrm{a}}$ Região - Rio de Janeiro, por excmplo, existem inclusive precedentes que explicitam o entendimento de que não há retenção de IRRF nas remessas a outros prestadores de serviços de telecomunicações situados no exterior. Nesse sentido, a Decisão n. 229/99, de 26 de agosto de 1999, publicada no Diário Oficial da União ("DOU") de 15 de dezembro de 1999:

Decisão n. 229/99, de 26/08/1999 -

Assunto: Imposto de Renda Retido na Fonte - IRRF

Ementa: REMFSSAS PARA O EXTERIOR. SERVIÇOS

DE TEL.EFONIA - TRÁFEGO SAINTE.

REGULAMENTO DE TELECOMUNICAÇÕES

INTERNACIONAL - RTI - EFICÁCIA. TRATADOS

INTERNACIONAIS PARA EVITAR DUPLA

TRIBUTAÇÃO DE RINDA - REGRAS ESPECIAS. DECISÕES ADMINISTRATIVAS - VINCULAÇÃO.

As remessas para o exterior realizadas por empresas de telecomunicações sediadas no Pais, em favor de empresas estrangeiras, pela prestação de serviços de complementação de ligações telcfônicas iniciadas no Brasil, só estão abrangidas pela regra exonerativa firmada pelo art. $6^{\circ}$ do RTI a partir de $19.10 .98 \ldots$

Similarmente, nas Soluções de Consulta ns. 145 e 146, datadas de 26 de julho de 2002, publicadas no DOU de 10 de setembro de 2002 (p. 9), a $7^{\text {a }}$ Região Fiscal assim manifestou-se:

EMENTA: REMESSAS PARA O EXTERIOR. SERVIÇOS DE TELEFONIA. TRÁFEGO SAINTE. REGULAMENTO DAS TELECOMUNICAÇÕES INTERNACIONAIS. É inexigivel o imposto de renda na modalidade fontc sobre a remessa de recursos ao exturior, em prol de operadora estrangeira domiciliada em país membro da LIT. como contraprestação pelo uso de sua rede de telecomunicações para completar chamadas iniciadas no Brasil.

DISPOSITIVOS LEGAIS: Decreto Legislativo 67/1998: Decreto 2.962/99; Constituição da União Internacional de Telecomunicações, arts. 4 e 54; Regulamento das Telecomunicações Internacionais, art. $6^{\circ}$ 
Posição conflitante com as descritas acima, contudo, encontra-se, como precedentemente mencionado, no Parecer AGU, segundo o qual o RIT não está em vigor no Brasil, não se aplicando, portanto, a isenção de que trata o art. 6.1.3.

Com base no Parecer AGU, a Superintendência Regional da Receita Federal em São Paulo afirmou ser "devido o imposto de renda na fonte sobre o total dos valores pagos, creditados, entregues. empregados ou remetidos às empresas com sede no exterior a titulo de pagamento pela contraprestação de serviços de telecomunicuções.. ". Para tal órgão da Receita Federal, a regra exoncrativa prevista no RIT não se aplica, "uma vez que referido tratado nunca foi examinado pelo Congresso Nacional, sendo sequer anexado ao Tratado de Nairobi e ao Tratado de Genebra, quando da apreciação desses tratados" 5 Finalmente, visando a uniformizar as divergências existentes, a ('oordenação-Geral de Tributação assim pronunciou-se:

ASSUNTO: Imposto de Renda Retido na Fonte IRRF
EMENTA: REMESSAS AO EXTERIOR. PAGAMENTO
PELA PRESTAÇÃO DE SERVIC OS DE
TELECOMUNICAÇOES. TRAFEGO "SAINTE"
OBRIGATOREDADE DE RETENÇÃO DE IMPOSTO DE
RENDA. É devido o Imposto de Renda na Fonte, à aliquota
de $15 \%$, sobre o total dos valores pagos, creditados,
entregues, empregados ou remetidos às empresas de
telecomunicações domiciliadas no exterior, a titulo de
pagamento pela contraprestação de serviços de
telecomunicações, relativos a chamadas de longa distância
internacionais, iniciadas no Brasil."

2.2. A UIT e os atos internacionais derivados: origens e lastro jurídico do RIT

A Convenção da UIT foi aprovada em 1947, na Conferência de Atlantic City. Dentre os objetivos da UIT, segundo seu ato constitutivo, figuram a manutenção e a ampliação da cooperação internacional para melhoria e a utilização racional de todo tipo de telecomunicação, assim como a assistência técnica aos países em desenvolvimento. Conta atualmente com a participação de cento e oitenta c nove países, seiscentos e cinqüenta e cinco membros interessados um seus serviços e sessenta associações de alcance regional. Sua composição, aliás, é indicativa de que essa organização

Ver Soluçōes de Consultas ns. 342 e 343, de 12 de dezembro de 2002.

Solução de Divergència n. 18, de 13 de outubro de 2003, publicada no DOL de 17 de outubro de 2003. 
internacional sc sustenta na cuoperação entre o público e o privadu. condição "indispensável paru o progressu dé um selor em constante e rápida mulação"

Ao longo dos anos, os atos internacionais pertinentes à Convenção è à Constituição da [II sofruram várias altcrações. É no Tratado de Genebra, firmado cm 22 de dezembro de 1992 ("Tratudo de Genebra"), que está consubstanciada a nova "Constituição e Convenção da LI'l"” O Tratado de Genebra entrou um vigor internacional em $1^{\circ}$ de julho de 1994 e passou a ter vigência no Brasil por força do Decreto n. 2.962, de 23 de fevereiro de 1999 ("Decreto n. 2.962'99").

Nenhum estudo sobre a vigência do RIT pode prescindir do exame de sua funte primária que é a UIT, destacando-se. em primeiro lugar, as disposições da Convenção Internacional de Telecomunicações também conhecida como Convenção de Nairobi (Quênia), celebrada em 06 de novembro de 1982 ("Tratado de Nairobi"8), da yual o Brasil foi signatário. O Tratado de Nairobi foi firmado, dentre outras, com a finalidade de facilitar as relações pacíficas, a cooperação internacional entre os povos c o desenvolvimento econômico e social, por meio do bom funcionamento das telecomunicações. É importante notar o disposto nos arts. 42 e 43 do Tratado de Nairobi sobrc os Regulamentos Administrativos:

ARTIGO 42 - Regulamentos Administrativos 170.1. As disposições da Convenção são complementadas pelos Regulamentos Administrativos, que regem a utilizaçãu das Telecomunicações e comprometem todos os membros. 171.2. A ratilicação da presente Convenção segundo o artigo 45. ou a adesão à mesma conforme o artigo 46, implica a aceitação dos Regulamentos Administrativos em vigor no momento dessa ratificação ou adesào.

172.3. Os Membros devem informar ao Secretário-Geral a sua aprovação de qualquer revisão desses regulamentos pelas Conferências Administrativas competentes. O SecretarioGeral notificará tais aprovações aos Membros à medida que as receber.

7 Ver a respcito SEITENFUS, Ricardo. Mamual das Organizações Internacionais. 3. ed. Porto Alegre: Livraria do Advogado Editora, 2003. p. 196-198, MELLO, Celso D. de Albuquerque. Curso de Direito Imlernacional Público. 12. ed. Rio de Janciro: Renovar, 2000. p. 679-678.

8 Como bem observa Celso D. de Albuquerque Mello. "a terminologia dos tratados é bastante impreciva na prítica internacional.. '., in op.cit., F. 200. No entanto, pode-se afirmar. com base em Hildebrando Accioly, que a melhor classificação é a que tem em vista a natureza juridica do ato. sendo os tratados divididos em tratados-contratos e tratados-lcis e/ou tratados-nomativos. Dentre os tratados-nomativos, podem ser citados os de criação de uniões intemacionais administrativas, como é o caso da União Postal Universal e o da UIT. Ver SILVA, G. E. do Nascimento; ACCIOLY, Hildebrando. Manual de Direito Internacional Público. 14. ed. São Paulo: Saraiva, 2000. p. 24-25. Dai, portanto. a preferência pela utilização de "Tratado de Nairobi" em vez de "Convenção de Nairobi" 
173.4. Em caso de divergència entre uma disposição da Convenção e uma disposição de um Regulamento Administrativo, a Convenção deverá prevalecer.

ARTIGO 43 Validade dos Regulamentos Administrativos em vigor

174. Os Regulamentos Administrativos mencionados no número 170.1. são aqueles em vigor no momento da assinatura da presente Convenção. São considerados como anexos à prescnte Convenção e permanecem válidos, sujeitos às revisões parciais que possam ser adotadas segundo os termos do número 53, até o momento da entrada em vigor de novos regulamentos elaborados pelas Conferências Administrativas Mundiais competentes e destinados a substitui-los como anexos da presente Convenção.

Os Regulamentos Administrativos em vigor no momento da assinatura do Tratado de Nairobi eram os Regulamentos Telegráfico e Telefônico e o Regulamento de Radiocomunicações. Tais Regulamentos, em vista do art. 43. 174. transcrito acima. foram considerados como anexos ao Tratado de Nairobi, complementando. assim, as disposições daquele (art. 42, 170.1.).

Consoante mencionado acima, em 09 de dezembro de 1988, na Conferência de Melbourne, foi aprovado novo Regulamento, ${ }^{9}$ o RIT, destinado a, na forma do mesmo art. 43, 174, "in fine" substituir os então vigentes (os Regulamentos Telegráfico c Telefônico) e integrar como anexo o Tratado de Nairobi. Nos termos do Protocolo Final da Conferência de Melbourne, as delegações dos Estados signatários, dentre as quais a Delegação Brasileira, tomaram conhecimento das declarações feitas por ocasião da assinatura dos Atos Finais da Conferência. A Delegação Brasileira declarou:
N. 23 Pela República Federativa do Brasil:
Pela assinatura destes Atos Finais, sujeita à aprovação pelo seu Congresso Nacional, a Delegação do Brasil reserva para o seu Governo o direito de tomar todas as medidas necessárias para salvaguardar scus interesses, na hipótese de outros Membros deixarem de observar as disposiçōes do Regulamento Internacional de Telecomunicações (Melbourne. 1988) e seus apêndices 1, 2 c 3 ou se as reservas formuladas por outros Membros puderem de alguma forma colocar em risco o bom funcionamento de seus serviços de telecomunicaçōes.

\footnotetext{
9 Conformi também precedentemente mencionado, o RIT vigora, no plano internacional, disde $1^{\circ}$ de julho de 1990.
} 
Em 30 de junho de 1989, foi subscrita a Conferência de Nice sobre a "Constituição e Convenção da UIT", com o objetivo de revogar e substituir o Tratado de Nairobi. Porém, antes que o Tratado de Nice pudesse entrar em vigor internacional, nova Conferência foi realizada, dessa vez em Genebra, na qual, em 22 de dezembro de 1992, resultou aprovado o Tratado de Genebra, o qual revogou o Tratado de Nairobi.

$\mathrm{O}$ art. $4^{\circ}$ do Tratado de Genebra estabelece quais são os instrumentos da UIT, ou seja, os documentos que dele fazem parte integrante:

Artigo $4^{\circ}$

Instrumentos da União

"29... Os instrumentos da União são:

-A presente Constituição da União Internacional de Telecomunicações,

-A Convenção da União Internacional de Telecomunicações. $\mathrm{e}$

- Os Regulamentos Administrativos.

30.2. A presente Constituição, cujas disposições se complementam com as da Convenção, é o instrumento fundamental da União.

31.3. As disposições da presente Constituição e da Convenção se complementam, ademais, com as dos Regulamentos Administrativos seguintes, que regulam o uso das telecomunicações e terão caráter vinculativo para todos os Membros:

Regulamento das Telecomunicações Internacionais, Regulamento de Radiocomunicações. (grifos do autor)

Já o art. 52 dispõe sobre a ratificação, a aceitação ou aprovação do Tratado de Genebra nos seguintes termos:

\begin{abstract}
Disposições Finais
Artigo 52

Ratificação, Aceitação ou Aprovação

208.1. A presente Constituição e a Convenção serão ratificadas, aceitas ou aprovadas. simultaneamente. $\mathrm{cm}$ um só instrumento. pelos Membros signatários, de conformidade com suas normas constitucionais. Tal instrumento será depositado, no mais breve prazo possivel, junto ao Secretário-Geral, que transmitirá a notificação pertinente aos Membros
\end{abstract}

Por fim, o art. 54 trata do caráter vinculativo dos Regulamentos Administrativos, dentre os quais o RIT: 
Artigo 54

Regulamentos Administrativos

215 1. Os Regulamentos Administrativos mencionados no artigo 4 da presente Constituição são instrumentos intemacionais obrigatórios e estarão sujeitos às disposições desta última e da Convenção.

2162 . A ratificação, aceitação ou aprovação da presente Constituição e da Convenção ou a adesão às mesmas, em razão dos artigos 52 e 53 da presente Convenção, inclui também o consentimento de obrigar-se pelos Regulamentos Administrativos, adotados pelas Conferências Mundiais competentes antes da data de assinatura da presente Consiituição e Convenção. Tal consentimento se entende como sujeição a toda reserva manifestada no momento da assinatura dos citados Regulamentos ou a qualquer revisão dos mesmos, sempre e quando ele se mantenha no momento de depositar o correspondente instrumento de ratificação, de aceitação, de aprovação ou de adesão.

(grifos du autor)

2.3. Integração do Tratado Internacional ao I Direito Interno brasileiro

Em que pesem as desavenças doutrinárias entre monistas e dualistas, ${ }^{10}$ é na Constituição Federal de 1988 ("CF") que se devem buscar os procedimentos relacionados à vinculação do Estado brasileiro a tratado internacional. Preceitua a CF, no art. 84, VIll, cumpetir privativamente ao presidente da República "celebrar tratados, convenções e atos internacionais, sujeitos a referendo do Congresso Nacional" Já o art. 49 da CF dispõe. em seu inciso I. sobre a competência exclusiva do Congresso Nacional para "resolver definitivamente sobre tratados, acordos ou utos internacionais que acarretem encargos ou compromissos gravosos ao patrimônio nacional"

A vinculação do Brasil a tratados internacionais resulta, assim, do concurso de duas vontades: a do Poder Executivo e a do Poder Legislativo. Ao presidente da República - que está investido dos poderes rulacionados à manutenção das relações exteriores - cabe a prerrogativa de determinar, discricionariamente, a iniciativa do processo legislativo de apreciação de tratado internacional. E, como bem assinala Pedro Dallari, o faz a partir do envio ao Congresso Nacional de mensagem, por meio da qual

10 Refoge aos objetivos deste artigo uma análise mais detalhada acerca das diferenças entre as duas correntes doutrinárias. Basta lembrar que. no Brasil, encontram-se adeptos tanto do dualismo, dentre os quais Amílcar de Castro, como do monismo (maior parte da doutrina) destacando-se, entre outros. Vicente Marotta Rangel e Celso D. de Albuquercue Mello. 
submete a senadores e deputados federais o texto do tratado celebrado pelo chefe do Poder Executivo em nome do País. " O Congresso Nacional outorga sua aprovação ao tratado internacional por meio da edição de decreto legislativo. IJma vez aprovado o tratado internacional pelo Congresso Nacional, fica o presidente da República habilitado a proceder ao ato de ratificação, cuja conseqüência é a vinculação do País na esfera internacional, bem como a, posteriormente à ratificação, promulgar o texto convencional, por meio de decreto publicado no Diário Oficial da União, para que produza efeitos na ordem jurídica interna.

Cachapuz de Medeiros assim resume as etapas desse processo: "a) inicia com a negociação e a adoção do texto, prossegue com a avaliação interna de suas vantagens ou inconvenientes e, no caso de ser aprovado, ocorre a manifestação da vontade do Estado em obrigar-se pelo tratado, o aperfeiçoamento juridico-internacional dessa vontade e a incorporação do texto do tratado à ordem juridica interna (negociação - assinatura - mensagem ao Congresso Nacional - aprovação parlamentar-ratificação - promulgação);" 12

\subsection{Formulação de reservas aos Tratados Internacionais}

Como assinala José Francisco Rezek, a "reserva é um qualificativo do consentimento" 13 Dessa forma, caso concorde com a maioria dos dispositivos de um tratado multilateral, mas refute alguns de seus aspectos, ao Estado é permitida a formulação de reservas. Instrumento característico dos tratados multilaterais, na correta expressão de Ricardo Seitenfus e Deisy Ventura, "a reserva objetiva excluir, do comprometimento do Estado, certos dispositivos acordados" Através de uma declaração de interpretação, "é possivel sublinhar o significado especial que o Estado deduz de certo dispositivo" 14 Díez de Velasco, a seu turno, define reserva "como uma declaração de vontade de um Estado que é ou vai ser parte de um tratado, formulada no momento da assinatura, no da ratificação e no de adesão, e que, uma vez que tenha sido autorizada expressa ou tacitamente pelos demais contratantes, forma parte integrante do próprio tratado" 15

$"$ Ver em Constituição e Tratados Internacionais. São Paulo: Saraiva, 2003. p. 89.

12 Conforme MFDFIROS, Antônio Paulo Cachapuz de. O poder de celebrar tratados: competência dos poderes constituidos para a celebração de tratados, à luz do direito internacional, do direito comparado c do Direito Constitucional brasileiro. Porto Alegre: Sérgio A. Fabris, 1995. p. 458.

13 Ver seu já consagrado livro Direiro dos Tratados. Rio de Janeiro: Forense, 1984. p. 336.

14 Conforme Introdução ao Direito Internacional Priblico. Porto Alegre: I ivraria do Advogado Editora, 2003. p. 47.

is Apud Celso D. de Albuquerque Mello, op.cit., p. 235. 
De acordo com a Convenção de Viena sobre o Direito dos Tratados de 1969 ("Convenção de Viena"), ${ }^{16}$ reserva significa "uma declaração unilaterul, qualquer que seja sua redação ou denominação, feita por um Estado ao assinar, ratificar, aceitar ou aprovar um tratado, ou a ele aderir, com o objetivo de excluir ou modificar os efeitos juridicos de certas disposições do Tratado em sua aplicação a esse Estado" (art. 2, 1, d)

Relevante notar das definições acima que a reserva pode ser apresentada não-somente no ato de assinatura de um tratado ou convenção, como também na ratificação, na aceitação e na adesão. Para ser válida, a reserva tem de ser apresıntada por escrito pelo poder competente dentro do Estado no tocante a assuntos internacionais. A reserva deve também ser aceita pelos outros contratantes.

As rescrvas podem ser classificadas de acordo com diversos critérios: (i) conforme sua natureza, i.e., reservas que excluem cláusulas e reservas interpretativas: (ii) tendo em vista o momento em que são formuladas, ou seja, na assinatura, na ratificação e na adesão; (iii) de acordo com sua extensão, i.e.. reservas legais e especiais; (iv) consoante o objeto e o fim do tratado, i.e., reservas compatíveis e incompativeis; e (v) em face de seus efeitos, ou seja, reservas que restringem ou ampliam o alcance do tratado. ${ }^{17}$

Apesar dessas definições e classificações, tem-se verificado na prática internacional uma expressiva quantidade de declarações unilaterais tidas equivocadamente como reservas. Não são enquadráveis como reservas pelo simples fato de não terem o objetivo de "excluir ou modificar os efeitos juridicos de certas disposições do Tratado" Excmplo clássico é a denominada "reserva de ratificação", manifustada por ocasião da assinatura do tratado ou convenção, por meio da qual, como lembra Rezek, se diz apenas o óbvio: que tal assinatura não obriga definitivamente o Estado ali representado, cuja ratificação, no momento oportıno, deverá ter esse efeito. Essa espécie de reserva, "rotundamente equivoca, desnuda de modo ainda mais constrangedor a injustificada insegurança dos delegados signatários quando o tratado é expresso e peremptório em estabelecer que só a ratificação obriga" 18

Um outro aspecto atinente às reservas que merece esclarecimento adicional ¿́ quanto à competência para formulá-las. Não há dúvidas de que cabe ao Poder Fxecutivo exteriorizar as reservas no plano internacional, quer na assinatura de um tratado, quer na

16 Embora o Brasil seja signatário da Convenção de Viena, ela ainda se encontra pendente de aprovação pelo Congresso Nacional e ratificaçào pelo Poder Executivo. Contudo, a Convenção de Viena tem valor juridico para todos os Estados pelo fato de ser internacionalmente reconhecida como norma "declaratória de direito internacional geral" Ver a usse respeito MAZZUOLI, Valèrio de Oliveira (Org.). Coletanea de Direito Imternacional. São Paulo: Editora Revista dos Tribunais, 2003. p. 187.

i: Conforme MELLO, Celso D. de Albuquerque. op.cit, p. 235.

18 Op.cit., p. 338. 
sua ratificação. Se apresentar reservas no ato de assinatura, deverá o Poder Executivo, quando da submissão do pertinente tratado à apreciação do Congresso Nacional, registrálas, caso seja sua intenção mantê-las no momento da ratificação. É facultado também ao Poder Executivo, que é o responsável pela negociação de um tratado, formular reservas quando de sua ratificação, indepındentemente de tê-las apresentado no ato de assinatura e, posteriormente, ao Congresso Nacional. A questão que se coloca, no entanto, é se cabe ao Congresso Nacional formular reservas na hipótese de o Poder Executivo delas não ter cogitado, ou acrescentar restrições àquelas já apresentadas por este. Acompanha-se aqui nesse tocante a posição de Rezek, segundo a qual não "pode haver divida de que, atento aos limites porventuru fluentes do tratado que examina, tem o Congresso Nacional o poder de aprová-lo com restrições - que o governo, à hora de ratificar, traduzirá em reservas -, como ainda o de aprová-lo com declaração de desabono às reservas acaso feitas na assinatura - e que não poderão ser confirmadas, desse modo, na ratificação" " 19 (grifos do autor) Cite-se, como exemplo, o Decreto Legislativo n. 74, de 1977, que aprova o texto da Convenção relativa à proteção do patrimônio mundial, cultural e natural:

Art. $1^{\circ}$ É aprovado o texto da Convenção Relativa à Proteção do Patrimônio Mundial. Cultural e Natural. aprovado pela Conferência Geral da Unesco, em sua XVII sessão, realizada em Paris, de 17 de outubro a 21 de novembro de 1972, com ressalva ao parágrafo I do art. 16. (grifos do autor)

Art. $2^{\circ}$ Este decreto legislativo entra em vigor na data de sua publicação.

Senado Federal, em 30 de junho de 1977.

Petrônio Portella

Presidente.

Observe-se que o Decreto I.egislativo transcrito acima demonstra não somente a competência do Congresso Nacional para aprovar com restrições um tratado internacional, como também a necessidade de que tais ressalvas sejam feitas com o objetivo específico "de excluir ou modificar os efeitos jurídicos de certas disposições" de um tratado (art. 2, 1, d, da Convenção de Viena).

19 Idem. pp. 347/348. Para Celso D. de Albuquerque Mello, o Legislativo não apresenta reservas. O que ele faz ć aprovar o tratado desde que o Poder Executivo apresente determinadas reservas. A apresentação de reservas ¿ um ato do Poder Executivo (op. cit., p. 269. nota n. 59). 
2.5. Vigência no Brasil do Tratado de Genebra e de seus documentos integrantes

Em conformidade com os procedimentos descritos acima, relacionados à vinculação do Estado brasileiro a tratado internacional, o Tratado de Genebra foi aprovado pelo Congresso Nacional por meio do Decreto Legislativo n. 67, de 15 de outubro de 1998 ("Decreto Legislativo n. 67/98"), cujo teor é o seguinte:

DECRETO LF.GISLATIVO N. 67, DE 1998

Aprova os textos $(*)$ dos Atos Finais da Conferência de PJenipotenciários Adicional, da União Internacional de Telecomunicações - UIT, aprovados pelos países membros em Genebra, em 22 de dezembro de 1992, e dos "Atos Finais da Conferência de Plenipotenciários", da União Internacional de Telecomunicações . UIT, aprovados pelos paises membros, em Quioto, em 13 de outubro de 1994.

O CONGRESSO NACIONAL, decreta:

Art $1^{\circ}$ São aprovados os textos dos Atos Finais da Conferência Adicional de Plenipotenciários de Genebra, ocorrida em 1992, e da Conferência de Plenipotenciários de Quioto, ocorrida em 1994, da União Internacional de Telecomunicações - UIT.

Parágrafo único. São sujeitos à aprovação do Congresso Nacional quaisquer atos que alterem os referidos Protocolos, assim como quaisquer ajustes complementares que, nos termos do art. 49, I, da Constituição Federal, acarretem encargos ou compromissos gravosos ao patrimônio nacional. Art $2^{\circ}$ Este Decreto Legislativo entra em vigor na data de sua publicação.

SENADO FEDERAL, EM 15 DE OUTUBRO DE 1998 Senador ANTONIO CARLOS MAGALHÃES

Presidente.

Em 19 de outubro de 1998, o Poder Executivo depositou Carta de Ratificação do Tratado de Genebra.

Note-se que nem o Congresso Nacional ao aprovar o Tratado de Genebra, nem o Poder Executivo ao ratificá-lo, formularam quaisquer reservas.

Foi editado, então, o Decreto n. 2.962/99, que promulgou o Tratado de Genebra nos seguintes termos:

DECRETO N. 2.962, DF 23 DE FEVEREIRO DE 1999

Promulga a Constituição e a Convenção da União Internacional de Telecomunicações, concluídas em Genebra, em 22 de dezembro de 1982, e seu instrumento de Emenda aprovado em Quioto, em 14 de outubro de 1994. 
O PRESIDENTE DA REPÚBLICA, no uso da atribuição que lhe confere o art. 84, inciso VIII, da Constituição,

CONSIDERANDO, que a Constituição e a Convenção da União Internacional de Telecomunicaçõcs foram concluídas em Genebra, em 22 de dezembro de 1992, e seu Instrumento de Emenda aprovado em Quioto, em 14 de outubro de 1994; CONSIDERANDO que o Congresso Nacional aprovou os atos multilaterais em epígrafe por meio do Decreto Legislativo n. 67. de 15 de outubro de 1998;

CONSIDERANDO que os Atos em tela entraram em vigor internacional $\mathrm{cm} 1^{\circ}$ de julho de 1994;

CONSIDERANDO que o Governo Brasileiro depositou o Instrumento de Ratificação dos referidos Atos em 19 de outubro de 1998, passando os mesmos a vigorar para o Brasil em 19 dc outubro de 1998;

DECRLTA:

Art. $1^{\circ}$ A Constituição e a Convenção Internacional de Telecomunicações, concluidas em (ienebra, 22 de dezembro de 1992, e suu Instrumento de Emenda aprovado em Quioto, em 14 de outubro de 1994, apensos por cópia a este Decreto, deverão ser executados e cumpridos tão inteiramente como neles se contém.

Art. $2^{\circ}$ Este Decreto entra em vigor na data de sua publicação.

Brasilia, 23 de fevereiro de $1999 ; 178^{\circ}$ da Independência e 1 I $1^{\circ}$ da República.

FERNANDO HENRIQUE CARDOSO

Luiz Felipe Lampreia.

Finalmente, em 24 de fevereiro de 1999, o Decreto n. 2.962/99 foi publicado no Diário Oficial da União.

É incontestável, pois, a vigência no Brasil do Tratado de Genebra e de todos os documentos que dele fazem parte integrante. inclusive os Regulamentos Administrativos, dentre os quais o RIT. Nesse tocante, o art. $4^{\circ}(29.1)$ do Tratado de Genebra é muito claro ao prescrever que são instrumentos da UIT sua Constituição e Convenção, bem assim os Regulamentos Administrativos. Ora, se esses documentos são parte integrante da UIT e "ipso facto" do Tratado de (ienebra. não há como se conceber que tal tratado possa ter sido aprovado, ratificado e promulgado sem que eles também não o tenham sido. ${ }^{20}$ É preciso lemtrar que boa parte dos tratados internacionais é composta

20 A afirmação contida no Parecer AGU de que o RIT nunca foi examinado nem sequer anexado ao Tratado de Genebra, por ocasiāo da apreciação daquele Tratado pelo Congresso Nacional, parece, pois. destituida de todo e qualquer fundamento. Tal afirmação equivale a dizer que o Congresso Nacional não foi diligente em sua apreciação dos dispositivos do Tratado de Genebra. Curioso é que o próprio autor do Parecer AGU acaba se contradizendo ao admitir, algumas linhas mais abaixo do mesmo parágrafo. que o RIT se encontra "vigente e eficaz internamente quanto às makirias não sujeitas à reserva legal.. ". Ora, se o RIT se encontra 
de anexos que dispõem sobre assuntos específicos relacionados a seu objeto. Aliás, existem tratados, dos quais os anexos constituem parte essencial. É o caso. por exemplo, da Convenção da ONU sobre o Direito do Mar de 1982 ("Convenção de Montego Bay").

O Tratado de Genebra, além de discriminar quais os documentos que o integram (art. $4^{\circ} 29,1$ ), no item 31.3., do mesmo art. $4^{\circ}$, estatui que as disposições da Constituição e da Convenção da UIT se complementam (ou seja, são essenciais e indissociáveis) com as dos Regulamentos Administrativos. dentre os quais as do RIT, e que estas últimas "terão caráter vinculativo para todos os Membros"

E mais: no art. 54 (2162), de maneira até redundante como que para evitar qualquer outro tipo de interpretação, prescreve que a ratificação, a accitação ou aprovação "da presente Constituição e da Convenção ou a adesão às mesmus, em razão dos arts. 52 e 53 da presente Convenção, inclui também o consentimento de obrigar-se pelos Regulamentos Administrativos, adotados pelas Conferências Mundiais competentes antes da data de assinatura da presente ('onstituição e Convenção" que é o caso do RJT. (grifos do autor)

Tendo em vista essas disposições do Tratado de Giencbra, resta evidente, portanto, que o Brasil também se obrigou a cumprir o RIT. Nesse tocante, mais relevante ainda é que ele foi aprovado e ratificado sem quaisquer rescrvas. Contudo, como algumas opiniões divergentes parecem se sustentar, dentre outros, no fato de o Brasil ter formulado reserva ao assinar o RIT, faz-se necessário analisar mais detidamente esse aspecto.

Conforme anteriormente destacado, ao subscrever os Atos Finais da Conferência de Melbourne, a Delegação brasileira lez a ressalva de que sua assinatura estava sujeita "à aprovação pelo seu Congresso Nacional" A rigor, tal declaração ou ressalva não constitui reserva. Não é reserva pelo simples fato de não ter o objelivo de "excluir ou modificar os efeitos juridicos de certas disposições do Tratado" Trata-se, isso sim, de manifestação, por meio da qual se diz apenas o óbvio: que tal assinatura não obriga definitivamente o Estado ali representado. cuja ratificação, no momento oportuno, deverá ter esse efeito. Essa espécie de "reserva de ratificação" é, para retomar a expressão de Rezek, "rotundamente equivoca"

Tal reserva poderia ter sido feita, no entanto, no momento da apreciação e da aprovação do Tratado de Genebra pelo Congresso Nacional. A esse respeito, como destacado por Rezek, tem o Congresso Nacional o poder de aprovar um tratado com

vigente e eficaz ainda que, segundo o Parecer $\mathrm{AGU}$, no que respeita as matérias nāo sujeitas à resurva legal (o que, frise-se, desde já, não é verdade), é porque foi efétivamente apreciado e aprovado pelo Congresso vacional. 
restrições - que o governo, à hora de ratificar, deverá traduzir em reservas. Assim, poderia o C'ongresso Nacional ter optado por excluir ou modificar os efeitos jurídicos de certas disposições do Tratado de Genebra e documentos dele integrantes, tais como as disposições do art. 6.1.3. do RIT. Nesse sentido, poderia o Congresso Nacional, em seu decreto legislativo, ter expressamente consignado a ressalva quanto a não-aplicação ao Brasil da isenção de que trata o art. 6.1.3. do RIT. Aliás, foi esse o procedimento que adotou ao editar o Decreto Legislativo n. 74, de 1977 aprovando o texto da Convenção relativa à proteção do patrimônio mundial, cultural e natural: "É aprovado o texto da Convenção Relativa à Proteção do Patrimônio Mundial, (ultural e Natural, aprovado pela Conferência Geral da Unesco, em sua X'VII sessão, realizada em Paris, de 17 de outubro a 21 de novembro de 1972, com ressalva ao parágrafo I do art. I6" (grifei) Poderia o Congresso Nacional. enfim, à luz do disposto no Art. 54 (216 2.) do Tratado de Genebra, manter ou reiterar expressamente a "reserva" formulada no ato de assinatura do RIT (i.e., não aprovando ou deixando para apreciar e aprovar separadamente o RIT em outra ocasião). Não o fez. Cingiu-se a aprovar os textos dos Atos Finais da Conferência de Genebra (1992) e de Quioto (1994), que, indiscutivelmente, incluem, o RIT, e, de modo genérico, a estipular que são sujeitos à aprovação do Congresso Nacional quaisquer atos que alterem os referidos Protocolos, assim como ajustes complementares que, nos termos do art. 49, l, da CF, acarretem encargos ou compromissos ao patrimônio nacional (parágrafo único do Decreto Legislativo n. 67/98). Ou seja: quaisquer atos ou ajustes complementares futuros que venham a alterar o Tratado de Genebra deverão ser novamente submetidos ao exame do Congresso Nacional.

Se tivesse, pois, o Congresso Nacional formulado qualquer tipo de reserva ao Tratado de Genebra, ao RIT ou a qualquer de seus dispositivos, notadamente, ao art. 6.I.3., deveria o Poder Executivo, poder competente dentro do Estado brasileiro no tocante a assuntos internacionais, tê-la reproduzido, por escrito, no ato de ratificação. Ademais, também poderia o Poder Executivo ter apresentado reservas quando da ratificação do Tratado de Genebra, independentemente de tê-las formulado no ato de assinatura ¿ de tê-las, posteriormente, submetido ao crivo do Congresso Nacional.

Como precedentemente enfatizado, ao depositar a Carta de Ratificação do Tratado de Genebra, em 19 de outubro de 1998, não apresentou o Poder Executivo nenhuma reserva, nem sequer manteve ou reiterou a "reserva" supostamente formulada no ato de assinatura do RIT, como deveria ou poderia ter feito em face do que dispõe o Art. 54 (216 2.) do Tratado de Genebra. Conseqüentemente, tal "reserva de ratificação" perdeu toda e qualquer validade. 
A principal conseqüência da ratificação de um Tratado é a vinculação do País na esfera internacional. Ao ratificar um Tratado, o País dá demonstrações inequivocas de sua disposição de cumprir as obrigações assumidas perante a comunidade internacional. Afinal, a ratificação é um ato que permite aos órgãos competentes do Estado meditar sobre o tratado, suas conseqüências e sua oportunidade, enfim, se ele é compativel com sua Constituição e reflete os interesses de sua sociedade. Se não houver reservas ou ressalvas, presume-se a plena satisfação de todos esses quesitos. Se a ratificação contiver reservas, é fundamental que os demais Tstados delas tomem conhecimento para saber como irão se posicionar nas relações que vierem a manter com o país que as adotou. ${ }^{21}$ É por isso que elas devem ser feitas por escrito, relacionando-se, de modo claro e específico, as disposições do tratado com as quais o Estado, após necessário processo de reflexão e de consulta à sociedade, não-concorda ou não pode se comprometer. Fica resguardada, assim, a segurança das relações internacionais.

Com efeito, sustentar ou pretender que o parágrafo único do Decreto Legislativo n. 67/98 constitui declaração de reserva relativamente ao Tratado de Genebra (i.e., ao RIT) é colocar o Brasil na condição de país que não tem apreço ou não-respeita princípio basilar de direito que é o da segurança jurídica das relações internacionais.

Assim é que, como o Brasil não fez nenhuma reserva expressa e específica em relação ao RIT, claro está que deverá cumprir irrestritamente suas disposições. Se não o fizer, estará violando um outro princípio geral de direito: o da boa-fé no cumprimento das obrigações internacionais.

\subsection{Vigência no Brasil do RIT e de seu art. 6.1.3}

Na medida em que nem o Congresso Nacional nem o Poder Executivo fizeram reserva expressa e especifica em relação ao RIT, as disposições deste devem ser cumpridas em sua integralidade, inclusive as de seu art. 6.1.3., que tratam da isenção de tributos nas remessas ao Exterior entre operadoras de telecomunicações referentes ao pagamento pelo tráfego sainte.

Nesse tocante, vale notar que, como afirmado no Parecer AGU, constitui a "exclusão tributária matéria fechada no âmbito estrito da reserva da lei, do principio da legalidade e da tipicidade.." e que "para que a isenção prevista pelo Regulamento de Melbourne seja incorporada ao Direito interno brasileiro, e tenha. no País, eficácia. necessário se faz à aprovação desse Regulamento Administrativo pelo Congresso

\footnotetext{
É preciso lembrar que a reserva também tem de ser accita pelos outros contratantes.
} 
Nacional, bem como a promulgação do mesmo por Decreto do presidente da República" Ora, se tanto o Congresso Nacional, por meio do Decreto Legislativo n. 67/98, como o Poder Executivo, por meio do Decreto n. 2.962/99, aprovaram e promulgaram, respectivamente, sem reservas, o Tratado de Genebra e seus documentos integrantes, como o RIT, ou scja, incorporaram-nos ao ordenamento jurídico brasileiro, é forçoso reconhecer que os princípios a que se refere o Parecer AGU, i.e., da legalidade e da tipicidade que devem embasar isenções tributárias, foram devidamente seguidos e observados.

É indubitável, assim, que a isenção tributária prevista no art. 6.1.3. do RIT esteja em vigor no Brasil, devendo. pois, ser plenamente aplicada, ainda que possa conflitar com o disposto no art. 685, inciso II, "a" do Regulamento do Imposto de Renda instituído pelo Decreto n. 3.000, de 26 de março de 1999.

Isso porque, como se sabe, os tratados têm, para usar a expressão de Alberto Xavier, "supremacia hierárquica" sobre a lei interna "e se encontram numa relação de especialidade em relação a esta" confirmada, em matéria tributária. pelo art. 98 do Código Tributário Nacional ("CTN") que, "em preceito declaratório", dispõe: "Os tratados e as convenções internacionais revogam ou modificam a legislação tributária interna e serão observados pela que lhes sobrevenha" Observe-se, enfim, diz ainda o renomado tributarista, "que o art. 98 do Código Tributário Nacional, tendo natureza de lei complementar, contém um comando adicional ao legislador ordinário, que veda a este, hierarquicamente, qualquer desobediencia ao tratado" 22 (grifos do autor)

Por seu turno, ao destacar a prevalência dos Tratados Internacionais sobre a legislação tributária interna imposta pelo art. 98 do CTN, o eminente desembargador federal, Hugo de Brito Machado, assim se manifestou: “...Os tratados internacionais, portanto devem ser respeitados pelo Congresso Nacional, que os referenda, e somente devem ser alterados pela via própria. Não por leis internas. Por outro lado, a alteração, por lei interna, de um tratado internacional, não tem apoio nos princípios da moralidade, que devem também presidir as relações internacionais. Alternado, por lei interna, regras de tratado internacional, o país perde credibilidade. Assim, temos fortalecido o nosso entendimento, no sentido de que os tratados internacionais não podem ser revogados pur lei interna. Tanto no pluno da ciência do direito, corno no plano ético" 2.

Constitui, portanto, o RIT documento integrante do Tratado de Genebra, em relação ao qual o Brasil não fez quaisquer reservas expressas e específicas. Como o

22 Ver XAVIER, Alberto. Direito Tributário Internacional do Brasil. 5. ed. Rio de Janeiro: Forense, 1998. p. 123-125.

23 In: Curso de Direiıo Tribuário. 19. ed. São Paulo: Malheiros. p. 73-74. 
Tratado de Genebra tem supremacia hierárquica sobre a lei interna e se encontra numa relação de especialidade em relação àquela, confirmada, em matéria tributária, pelo art. 98 do CTN, deverá o Brasil cumprir integralmente suas disposições, inclusive a de seu art. 6.1.3.

Em 15 de outubro de 2004, foi editado, pelo Secretário da Receita Federal, - Ato Declaratório Interpretativo SRF n. 25, o qual ratifica o entendimento das autoridades fiscais brasileiras acerca da incidência do IR sobre as remessas para pagamento de serviços de telecomunicações. Trata-se de medida que naturalmente não tem, e nem poderia ter, o efeito de afastar a aplicação de um Tratado Internacional, devidamente ratificado pelo Brasil sem quaisquer reservas expressas e específicas.

A recusa do Brasil em reconhecer a vigência do RIT e, em especial, a de seu art. 6.1.3., configura, a toda evidência, violação do princípio satisfatório da UIT. Trata-se tal artigo de norma jurídica vinculante que estipula a obrigação de se oferecer aos usuários um serviço de telecomunicações de acordo com "parâmetros econômicos adequados" Como visto, a isenção de tributos nas remessas ao Exterior entre operadoras de telecomunicações referentes ao pagamento pelo tráfego sainte (i.e., pagamentos efetuados por contraprestação de serviços de telecomunicações internacionais) tem por objetivo criar um ambiente econômico favorável à prestação de serviços internacionais de telecomunicações e seus usuários, além de ser medida perfeitamente afinada com um dos objetivos da UIT que é o de ampliar a cooperação internacional para melhoria e a utilização racional de todo tipo de telecomunicação.

\section{Violação do Princípio do Tratamento Nacional do GATS}

3.1. Características tecnológicas e comerciais do provimento de capacidade de satélite

Ao estabelecer que o provimento de capacidade de satélite estrangeiro no Brasil deva ser feito pelo representante legal da operadora estrangeira, por meio de contrato por ele firmado com empresa de telecomunicações no Brasil, e que o correspondente pagamento deva ser efetuado em moeda corrente nacional, ${ }^{24}$ a Anatel nãosomente age em discordância com os principios do tratamento nacional do GATS (e satisfatório da UIT), como também desconsidera as características tecnológicas e comerciais desse serviço, o qual, para os efeitos deste estudo, será denominado Serviço de Transporte de Sinais de Telecomunicações via Satélite ("SSTS"). 25

24 Ofício Circular Anatel n. 004/2001.

25 Ainda que, segundo a LGT, o provimento de capacidade de satélite não seja serviço de telecomunicações. 
Em geral, o SSTS ¿́ uscolhido por empresas que necessitam de uma conectividade mundial/global para sua rede privada de comunicações, que propicie acesso imediato, grande largura de banda para transmissão de suas informações, bem assim soluções reais para o desenvolvimento e a operação dessa rede.

Inúmeras são as razões que levam as empresas a contratar o SSTS, em ve7 de transmitirem seus dados por meio de redes de fibras ópticas ou qualquer outro meio tecnológico disponível. A principal delas é que somente uma rede de satélites possui uma conectividade global capaz de atender, de mancira rápida e eficiente, as áreas mais remotas do globo e/ou aquelas com enorme déficit de infra-estrutura terrestre.

Para que a rede de satélites seja capaz de executar tais atividades de maneira eficaz (i.e., de forma a atender o elevado nível de exigência das empresas), é necessária a realização de vultosos investimentos no desenvolvimento, na produção, no lançamento, na operação e na manutenção dos satélites. Ou seja, é necessário investir grandes recursos para criar-sc uma estrutura capacitada para atender ao expressivo número de usuários que desejam: (i) atingir áreas remotas e/ou com (quase) nenhuma infra-estrutura terrestre; (ii) a conectividade total e global de sua rede privada de telecomunicações; (iii) alto desempenho: (iv) o estado da arte tecnológico nos processos de transmissão de dados, voz, e comunicações multimídias; e (v) um sistema de comunicação confiável.

Foi justamente por força desses altos investimentos que se concebeu um modelo internacional de negócios entre as empresas usuárias e as operadoras de SSTS, cujo objetivo é a redução do preço do SSTS, tornando-o, assim, econômica e comercialmente viável. Esse modelo que, na prática, tem, de fato, permitido uma drástica redução do preço cobrado pelas operadoras de SSTS, consiste, essencialmente, na contratação do SSTS com características globais/internacionais. Ou seja, as empresas usuárias do SSTS têm suas necessidades de comunicação atendidas simultaneamente em diversas regiões do planeta.

lmagine-se. por exemplo. uma empresa que tenha subsidiárias em diversos países e que necessite integrá-las por meio de sua rede privada de telecomunicações. $\Lambda$ matriz dessa empresa, que pode estar localizada em qualquer pais, Paraguai, Estados Unidos, Japão, Portugal, Brasil ou Austrália, contrata o provimento de SSTS de uma operadora de rede de satélites com cobertura mundial, porque acredita ser essa uma solução para todas as suas necessidades de telecomunicações com suas subsidiárias espalhadas pelo mundo. Como se trata de um grande segmento de capacidade espacial comercializado de uma única vez. a empresa contratante da capacidade pode obter melhores condições de preço e de formas de pagamento. 
Claro está, portanto, que o SSTS somente é viável do ponto de vista econômico se comercializado globalmente, isto é, em escala mundial/internacional. A adoção desse modelo de provimento global/internacional de capacidade de satélite, além das vantagens tecnológicas, propicia uma redução nos custos das empresas que fazem uso dessa capacidade, beneficiando, em última instância, os usuários finais de serviços de telecomunicações, inclusive os brasileiros. Vale lembrar que esse é um dos objetivos da UIT e da própria LGT.

3.2. O requisito do contrato de SSTS com o representante legal: modificação das condições de competição em favor dos operadores nacionais

Em face dessa caracteristica tecnológica e comercial do provimento de SSTS, é fácil perceber que o "business plan" das operadoras de SSTS, isto é, o cálculo de scus custos, do impacto fiscal e de sua margem de lucro, seja feito de maneira global. Isso requer a assinatura de um contrato internacional entre a operadora de SSTS e a matri $\mathrm{da}$ empresa usuária, independentemente do local de sua sede. ("muster agreement"), que. além de estipular o preço global (i.e., comercialização de uma única vez, válida para todas as suas subsidiárias espalhadas pelo mundo). estabeleça as condições gerais do provimento do SSTS.

O requisito da Anatel, lastreado, aliás, em duvidosa interpretação da LGT e da Resolução n. 220/00, no tocantc ao provimento de capacidade de satélite estrangeiro a empresas de telecomunicações nacionais choca-se frontalmente com tal característica do SSTS, a ponto de torná-lo inviável.

Isso porque, na perspectiva da Anatel, a operação poderia ou deveria ser realizada da seguinte forma: o representante legal da operadora estrangeira compraria ou locaria a capacidade de satélite, revendendo-a ou sublocando-a à empresa brasileira; o pagamento por esta última seria feito em moeda corrente nacional, ficando a operação sujeita aos impostos incidentes; finalmente, a remessa para o exterior (i.e., para a operadora estrangeira do satélite) pelo representante legal dos valores auferidos com a "revenda ou sublocação" da capacidade do satélite, estaria sujeita à incidência de IRRF à aliquota de $25 \%$ ou $15 \%$, conforme o caso.

Segundo justificativas apresentadas de modo não oficial (e, porque não dizer, de maneira falaciosa ${ }^{26}$ ) pela Anatel, esse modelo teria por linalidade equilibrar as

26 Saliente-se a respeito que a Anatel sempre hesitou em definir claramente e de maneira precisa quais as funções do representante legal da operadora de satélite estrangeiro no Brasil. Com efcito, desde a vigência do 
condições de competição entre as operadoras de satélite estrangeiras e as nacionais, já que as primeiras teriam vantagens comparativas caso não estivessem sujeitas ao pagamento dos impostos locais.

$O$ efeito, na prática, desse modelo é. sem dúvida, o de modificar as condições de competição cm favor das operadoras nacionais de satélite, ou seja, é repassar o denominado "Custo Brasil" para o operador de satélite estrangeiro, o que viola o princípio do tratamento nacional do GATS.

Ademais, esse modelo, na medida em que se assenta em critérios ou parâmetros econômicos inadequados c que não resultam em benefícios para os usuários (pelo contrário, ao afastar a concorrência de operadores de satélites estrangeiros, propicia o aumento do preço do serviço), infringe o princípio satisfatório da UIT.

\section{Conclusões}

Ao negar vigência à isenção tributária de que trata o art. 6.1.3. do RIT, o Brasil está violando o princípio satisfatório da UIT. Também infringe o princípio satisfatório ao conceber modelo de provimento de capacidade de satélite estrangeiro que, por não seguir critérios ou parâmetros econômicos adequados, elimina a competição e prejudica os usuários do serviço. Ao eliminar a competição ou modificar as condições de competição em favor das operadoras de satélite nacionais, ferc o principio do tratamento nacional do GATS.

A natureza vinculante desses princípios impõe ao pais a obrigação de adotar certas condutas e politicas compatíveis com os interesses da comunidade internacional. A relutância em adotá-las coloca o Brasil na condição de país que não tem apreço pela segurança jurídica das relações internacionais nem pela boa-fé no cumprimento das obrigações internacionais.

São Paulo, agosto de 2005.

Decreto n. 2.195, de 08 de abril de 1997, as funçôes do representante legal da opuradora de salcilitc estrangeiro tèm sido vaga e ambiguamente estabelccidas gerando grande confusão no mercado. 


\section{Referências}

DALLARI, Pı̀dro. Constituiçāo e Tratados Internacionais. São Paulo: Saraiva, 2003.

MAZZUOLI, Valério de Oliveira. Coletänea de Dircito Internacional. São Paulo: Ed. Revista dos Tribunais, 2003.

MEDEIROS, Antônio Cachapuz di. O poder de celebrar tratados: competîncia dos poderes constituidos para a celebração de tratados, à luz do Direito Internacional, do Direito Comparado e do Direito Constitucional Brasileiro. Porto Alegre: Sírgio A. Fabris, 1995.

MELLO. Celso D. de Albuquerque. Curso de Direito Internacional Puiblico. 12. ed. Rio de Janeiro: Renovar, 2000.

SILVA, G. E. do Nascimento e; ACCIOLY, Hildebrando. Manual de Direito Internacional Público. 14. ed. São Paulo: Saraiva, 2000.

RANGEL, V Marotta. Direito e Relações Internacionais. 7. ed. São Paulo: Ed. Revista dos Tribunais, 2002 .

RF.Z.EK, José lrancisco. Direito dos Tralados. Rio de Janeiro: Forense, 1984.

RODAS, João Grandino. A Constituinte e us Tratados Internacionais. Revista dos Tribunais, São Paulo, v. 76, n. 624, 1987.

RODRIGUFS, José Rubens Andrade Fonseca. Principios Gerais de Direito Internacional de Telecomunicação e a Lei n. 9.472/97 da República Federativa do Brasil ("Lei Geral de Telecomunicações"). 2004. Tese(Doutorado) Faculdade de Direito da Universidade de São Paulo, São Paulo.

SEITENFUS. Ricardo. Manual das Organizaçôes Internacionais. 3. ed. Porto Alegre: Livraria do Advogado Editora, 2003.

SEITENFUS, Ricardo: VENTURA, Deisy. Introdução ao Direito Internacional Público. Porto Alegre: Livraria do Advogado Editora, 2003.

THORSTENSEN. Vera. OMC - Organização Mundial do Comércio: as regras do Comércio Internacional e a Nova Rodada de Negociações Multilaterais. 2. ed. São Paulo: Aduaneiras, 200I.

TRINDADE, Antônio Augusto Cançado. Princípios do Direito Internacional Contemporáneo. Brasilia: Ed. Lniversidade de Brasília, 1981.

XAVIFR, Alberto. Direito Tributário Internacional do Brusil. s. ed. Rio de Janeiro: Forense, 1998. 